\title{
МОНИТОРИНГ ЦИФРОВОЙ ТРАНСФОРМАЦИИ КАК УСЛОВИЕ СТРАТЕГИЧЕСКОГО РАЗВИТИЯ РЕГИОНАЛЬНЫХ ХОЗЯЙСТВЕННЫХ СИСТЕМ
}

\author{
(c) 2021 Кулагина Наталья Александровна \\ доктор экономических наук, профессор, профессор кафедры «Государственное управление, \\ экономическая и информационная безопасность» \\ Брянский государственный инженерно-технологический университет, Россия, Брянск \\ E-mail: Kulaginana2013@yandex.ru \\ (C) 2021 Гавричкова Яна Владиславовна \\ магистрант кафедры «Государственное управление, экономическая \\ и информационная безопасность» \\ Брянский государственный инженерно-технологический университет, Россия, Брянск \\ E-mail: Ignatovay12@mail.ru \\ (C) 2021 Карпенко Павел Алексеевич \\ соискатель Высшей инженерно-экономический школы \\ Санкт-Петербургский политехнический университет имени Петра Великого, Россия, Санкт- \\ Петербург \\ E-mail: karpenko_pavel@mail.ru
}

Формирование новой модели региональной экономической политики современных регионов России осуществляется на основе применения сквозных цифровых технологий, которые затрагивают важнейшие качественные параметры конкурентоспособности хозяйственных систем, создают условия для инновационного роста и инвестиционной привлекательности. При этом одним из важнейших факторов, определяющих оперативность принимаемых управленческих решений по активизации процессов цифровизации является наличие соответствующей информационной базы в системе мониторинга уровня цифрового развития. Методологическая и практическая значимость выполненного исследования заключается в практическом использовании разработанного алгоритма организации системы мониторинга для разработки основных положений Стратегии цифрового развития отдельных территорий.

Ключевые слова: алгоритм, мониторинг, региональная хозяйственная система, стратегия, цифровизация, цифровая активность, цифровой потенциал.

Современное развитие экономики России и ее отдельных регионов определяются темпами внедрения цифровых технологий для повышения эффективности предоставления государственных и муниципальных услуг, оптимизации бизнес-процессов, качественной трансформации отдельных секторов экономики для обеспечения национальных целей и задач Стратегии национальной безопасности [6].

Совершенствование стратегий социальноэкономического развития отдельных регионов направлено на включение и корректировку имеющихся показателей, отражающих процессы цифровизации, так как использование сквозных цифровых технологий определяет инновационность производимой продукции, работ, услуг, способствует улучшению инвестиционного кли- мата и обеспечивает конкурентные преимущества региональных систем, как на внутреннем, так и на внешнем рынке [7].

Уровень цифрового развития региональной хозяйственной системы зависит от качественной оценки происходящих процессов, учета специфических особенностей ИКТ-сектора региона, инициатив по разработке и внедрению сквозных цифровых технологий, совершенствования информационной функции региональных органов власти и ряда других параметров, которые необходимо учитывать для разработки комплексной программы развития цифровых систем различного уровня [3].

Одним из важнейших аспектов стратегического развития цифрового потенциала региона является совершенствование системы монито- 
ринга факторов, определяющих уровень цифровой трансформации и качественное значение показателей, определяющих уровень цифровизации экономики на основе соответствующих алгоритмов оценки [2].

По нашему мнению, целесообразно создание единой информационно-аналитической платформы, на основе которой необходимо проводить мониторинг процессов цифровизации с целью последующей оценки их эффективности и изучения корреляционной зависимости с показателями социально-экономического развития [1].

Это объясняется тем обстоятельством, что важнейшими целевыми показателями развития региональных хозяйственных систем с использованием сквозных цифровых технологий являются достижение высокого уровня жизни и качества населения [4].
Имеющийся опыт разработки алгоритмов и методов организации мониторинга социальноэкономических систем позволил предложить авторский механизм мониторинга уровня цифрового развития региональных хозяйственных систем с учетом специфических особенностей их функционирования (рис.1).

Как видим, в составе предлагаемого алгоритма одним из важнейших аспектов выступает комплексная оценка имеющегося цифрового потенциала и факторов, определяющих цифровую активность региона, на основе которых осуществляется разработка приоритетных целей и задач цифрового развития.

Несомненным положительным аспектом при внедрении предлагаемой информационноаналитической системы мониторинга является связь с региональными и национальными проектами по цифровой экономике, а также воз-

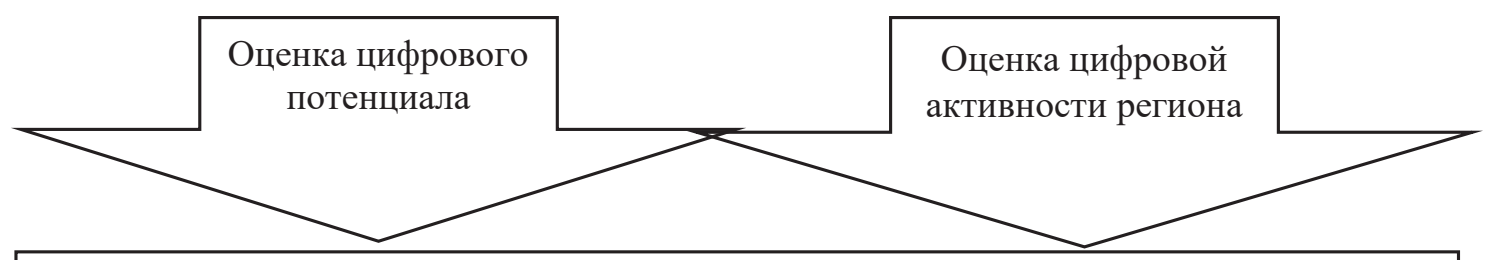

Определение приоритетных целей и задач цифрового развития

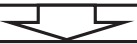

Сбор и систематизация основных источников информации о процессах цифровизации, как в регионе, так и в стране в целом

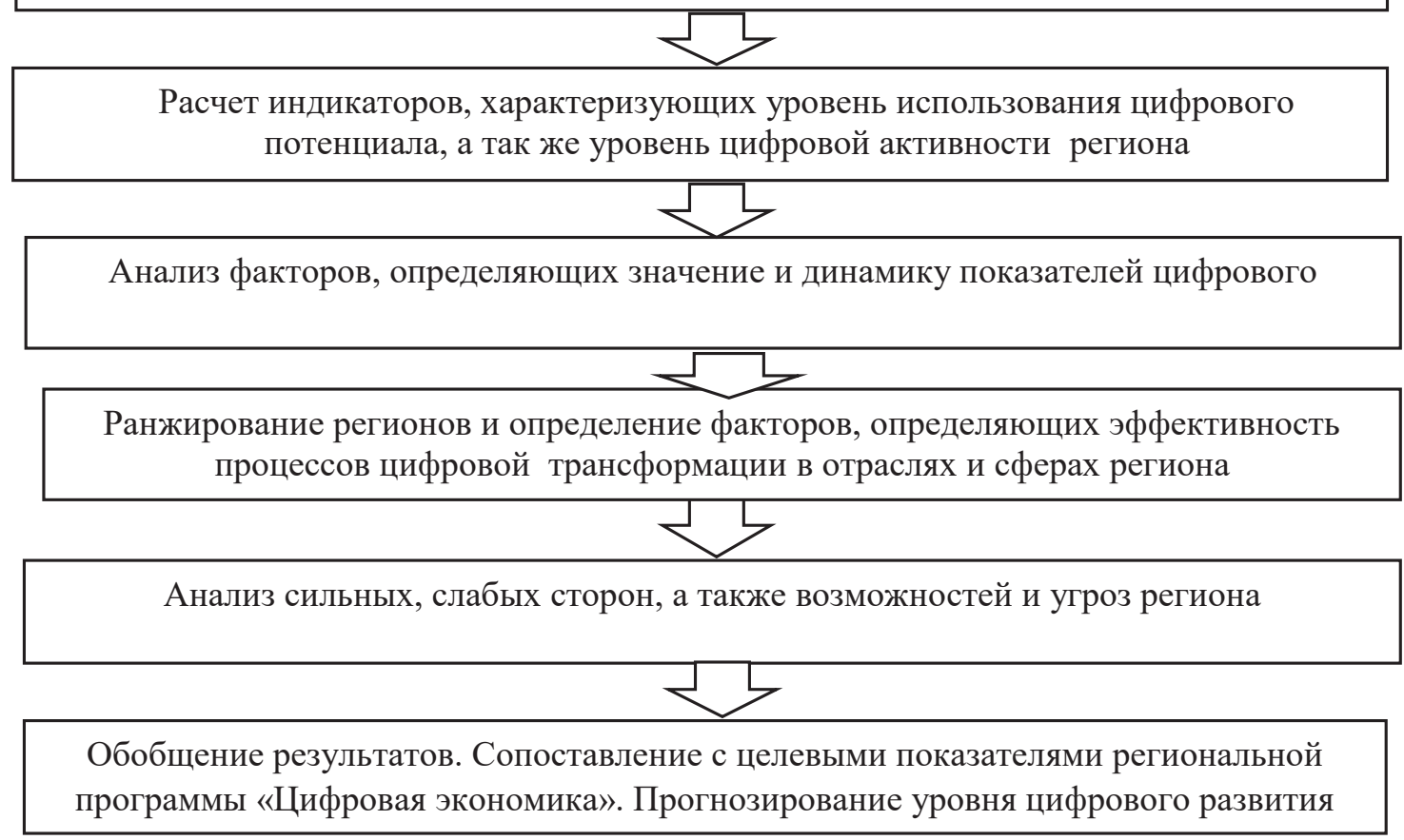

Рисунок 1. Предлагаемый алгоритм системы мониторинга уровня цифрового развития региональных хозяйственных систем 
можность расчета системы индикативных показателей, позволяющих оценить достижение поставленных целей цифрового развития региона.

Предлагаемая система мониторинга уровня цифрового развития может быть реализована на базе Ситуационных центров Губернаторов, так как взаимодействует с рядом онлайн-сервисов, определяющих работу органов исполнительной власти, например, с системой «Электронный бюджет» и т.д.

В частности, расчет предлагаемой системы аналитических показателей для оценки цифрового потенциала и возможностей цифрового развития возможно на основе единой цифровой платформы, которая, по нашему мнению, схематично может быть представлена следующим образом (рис. 2).

Реализация системы мониторинга осуществляется на основе Постановления Правительства РФ от 31.10.2018 N 1288 (ред. от 24.06.2021) «Об организации проектной деятельности в Правительстве Российской Федерации» (вместе с «Положением об организации проектной деятельности в Правительстве Российской Федерации»).

Мониторинг реализации региональных проектов по цифровой трансформации, должен осуществляться, на наш взгляд, на основе Цифрового паспорта региона, информация которого формируется нарастающим итогом из цифровых паспортов муниципалитетов.

Анализ действующей политики региональных органов власти относительно учета процессов цифровизации показал, что в настоящее время не разработана единая форма цифрового паспорта, что затрудняется процесс адекватной оценки процессов цифровой трансформации и их комплексного исследования для своевременного принятия соответствующих управленческих решений.

Структура паспорта цифрового развития территории (муниципального образования), предлагаемая нами для использования в качестве исходной информационной базы единой системы мониторинга региональных процессов

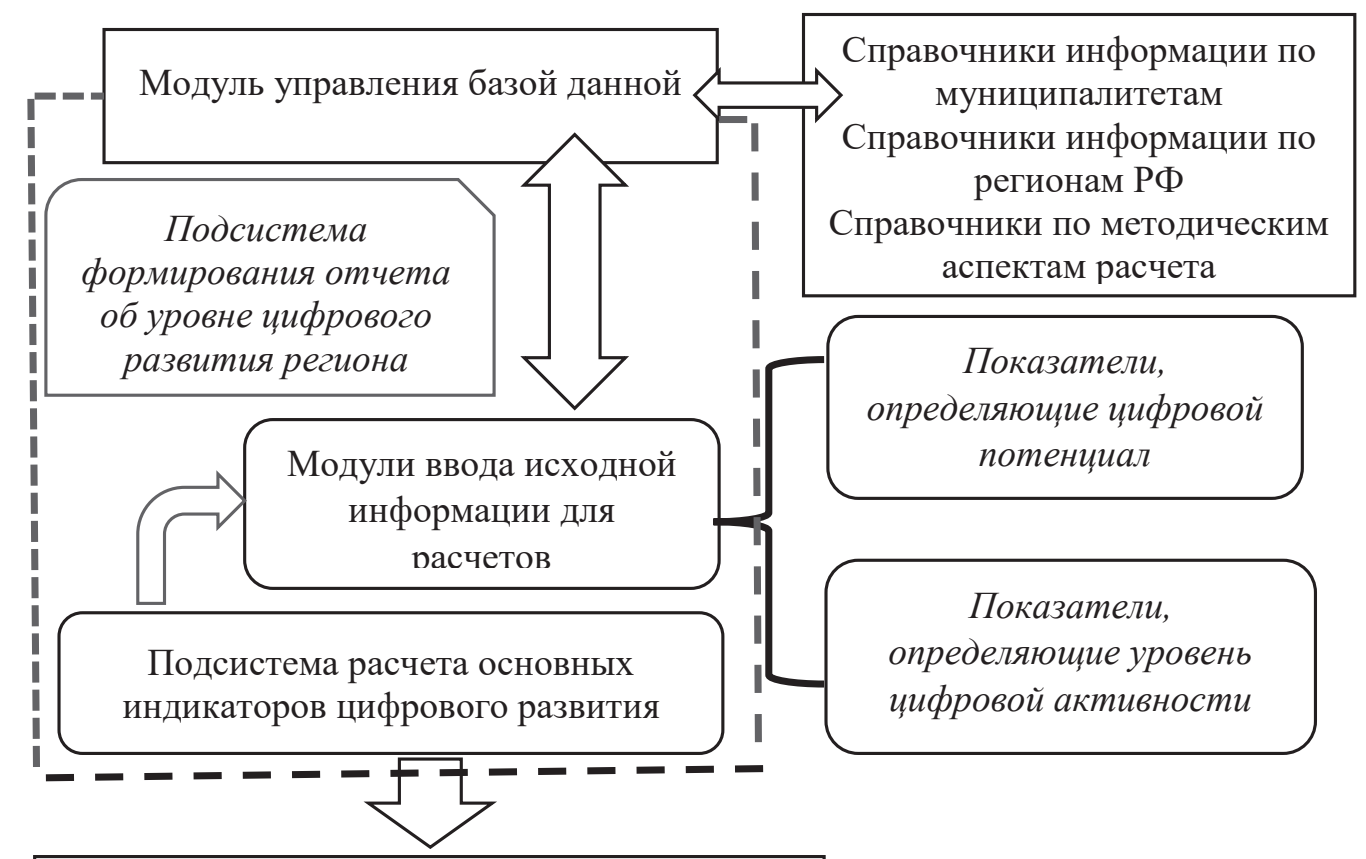

Модуль приведения показателей в

сопоставимый вид;

Модуль расчета показателей динамики;

Модуль комплексной оценки;

Модуль ранжирования регионов

(муниципалитетов)

Модуль прогнозирования индикаторов

Рисунок 2. Структурная схема предлагаемого программного продукта для оценки и прогнозирования уровня цифрового развития региона 
цифровизации, представлена в таблице 1.

Заполнение цифровых паспортов целесообразно помесячно, ежеквартально, нарастающим итогом, что позволяет получить оперативную информацию для оценки уровня цифрового развития муниципалитета, региона и выявле- ние основных качественных характеристик регионального цифрового развития по сравнению с другими регионами.

Особенностью предлагаемой системы мониторинга является использование достоверной фактической информации по достижению ос-

Таблица 1. Предлагаемая структура Цифрового паспорта территории для мониторинга уровня цифрового развития региона

\begin{tabular}{|c|c|}
\hline Наименование муниципалитета: & $\begin{array}{c}\text { Значение } \\
\text { показателя }\end{array}$ \\
\hline \multicolumn{2}{|l|}{ Показатели, характеризующие цифровой потенциал } \\
\hline $\begin{array}{l}\text { Удельный вес домашних хозяйств, имеющих широкополосный доступ к интернету, в общем } \\
\text { числе домашних хозяйств }\end{array}$ & $\%$ \\
\hline Удельный вес продукции цифрового назначения в ВРП & $\%$ \\
\hline $\begin{array}{l}\text { Абоненты широкополосного доступа к фиксированному интернету в расчете на } 100 \text { чел. насе- } \\
\text { ления }\end{array}$ & ед. \\
\hline Абоненты широкополосного доступа к мобильному интернету в расчете на 100 чел. населения & ед. \\
\hline $\begin{array}{l}\text { Удельный вес домашних хозяйств, имеющих широкополосный доступ к интернету, в общем } \\
\text { числе домашних хозяйств }\end{array}$ & $\%$ \\
\hline Число персональных компьютеров на 100 работников с выходом в интернет & ед. \\
\hline $\begin{array}{l}\text { Удельный вес численности студентов, обучающихся по IT-направлениям подготовки от общей } \\
\text { численности обучающихся по программам высшего образования }\end{array}$ & $\%$ \\
\hline $\begin{array}{l}\text { Удельный вес численности обучающихся по ІТ-направлениям подготовки от общей численно- } \\
\text { сти обучающихся по программам среднего образования }\end{array}$ & $\%$ \\
\hline Уровень обеспеченности высококвалифицированными кадрами цифрового сектора экономики & $\%$ \\
\hline Удельный вес затрат на кибер-безопасность в общей величине затрат субъектов & $\%$ \\
\hline $\begin{array}{l}\text { Удельный вес населения, получивших образование по цифровым компетенциям по програм- } \\
\text { мам ДПО от общей численности }\end{array}$ & $\%$ \\
\hline $\begin{array}{l}\text { Удельный вес персонала, занятого научными исследованиями и разработками, от общей чис- } \\
\text { ленности занятых }\end{array}$ & чел. \\
\hline $\begin{array}{l}\text { Уровень обеспеченности нормативно-правовыми актами, регулирующими региональных про- } \\
\text { цессы в сфере цифровизации }\end{array}$ & $\%$ \\
\hline Удельный вес инновационно-активных предприятий от общей численности предприятий & $\%$ \\
\hline Удельный вес предприятий ИКТ сектора от общей численности предприятий & $\%$ \\
\hline Удельный вес домашних хозяйств, имеющих персональный компьютер & $\%$ \\
\hline \multicolumn{2}{|l|}{ Показатели, определяющие цифровую активность: } \\
\hline $\begin{array}{l}\text { Удельный вес закупаемого (арендуемого) отечественного ПО от общего объема закупок про- } \\
\text { дукции ИКТ назначения }\end{array}$ & $\%$ \\
\hline $\begin{array}{l}\text { Удельный вес организаций, использовавших специальные программные средства для научных } \\
\text { исследований }\end{array}$ & $\%$ \\
\hline $\begin{array}{l}\text { Удельный вес организаций, использовавших специальные программные средства для управ- } \\
\text { ления автоматизированным производством и/или отдельными техническими средствами и } \\
\text { технологическими процессами }\end{array}$ & $\%$ \\
\hline Удельный вес организаций, использовавших CRM, ERP, SCM - системы & $\%$ \\
\hline Удельный вес организации, использовавшие системы электронного документооборота & $\%$ \\
\hline Внутренние затраты на научные исследования и разработки & млн.руб. \\
\hline Удельный вес затрат на разработку цифровых проектных решений в общей величине затрат, \% & $\%$ \\
\hline Внутренние затраты на фундаментальные исследования & млн.руб. \\
\hline Внутренние затраты на прикладные исследования & млн.руб. \\
\hline Выдано патентов на полезные модели и изобретения & ед. \\
\hline Наличие муниципальных центров цифровой подготовки & ед. \\
\hline Наличие муниципальных цифровых платформ & ед. \\
\hline
\end{tabular}


новных показателей цифрового развития, что представляет собой базу для принятия стратегических мер поддержки в разрезе отдельных отраслей и сфер экономики. Также имеется возможность выявлять риски цифрового развития на основе критических значений аналитических показателей.

Результаты системы мониторинга являются исходной базой при разработке и корректировке Стратегии Цифрового развития региона, работа над которой, на наш взгляд, может быть систематизирована в три последовательно вытекающих друг друга этапов:

1) этап стратегического анализа текущего уровня цифрового развития на основе оценки цифрового потенциала и уровня цифровой активности региона;

2) этап формирования желаемого уровня цифрового развития региона и учета всей совокупности факторов его развития;

3) организационные меры управления процессом достижения разработанной стратегии.

Для практической реализации Стратегии цифрового развития целесообразно использовать инструменты проектного управления, с помощью которого достигается эффективность за счет закрепления конкретных этапов по от- ветственным лицам и определяется степень их персональной ответственности.

На основе концепции проектного управления нами была сформулирована логическая последовательность основных этапов Стратегии цифровизации региона (рис. 3).

Использование на практике предлагаемого алгоритма позволит повысить эффективность управленческих решений по цифровой трансформации отраслей и сфер экономики за счет установления конкретных временных рамок и комплексного исследования факторов, определяющих использование цифрового потенциала региона.

Для более детальной проработки мероприятий по каждому из этапов Стратегии Цифрового развития региона целесообразно воспользоваться, на наш взгляд, подходом «стратегические линзы», элементы которого представлены на рисунке 4.

При планировании комплекса мероприятий по повышению уровня цифрового развития регионов и отдельных муниципалитетов, в частности, целесообразно использовать в качестве основы программно-целевой подход, который обладает рядом преимуществ:

1) имеющийся эффективный опыт использования при разработке различных программ

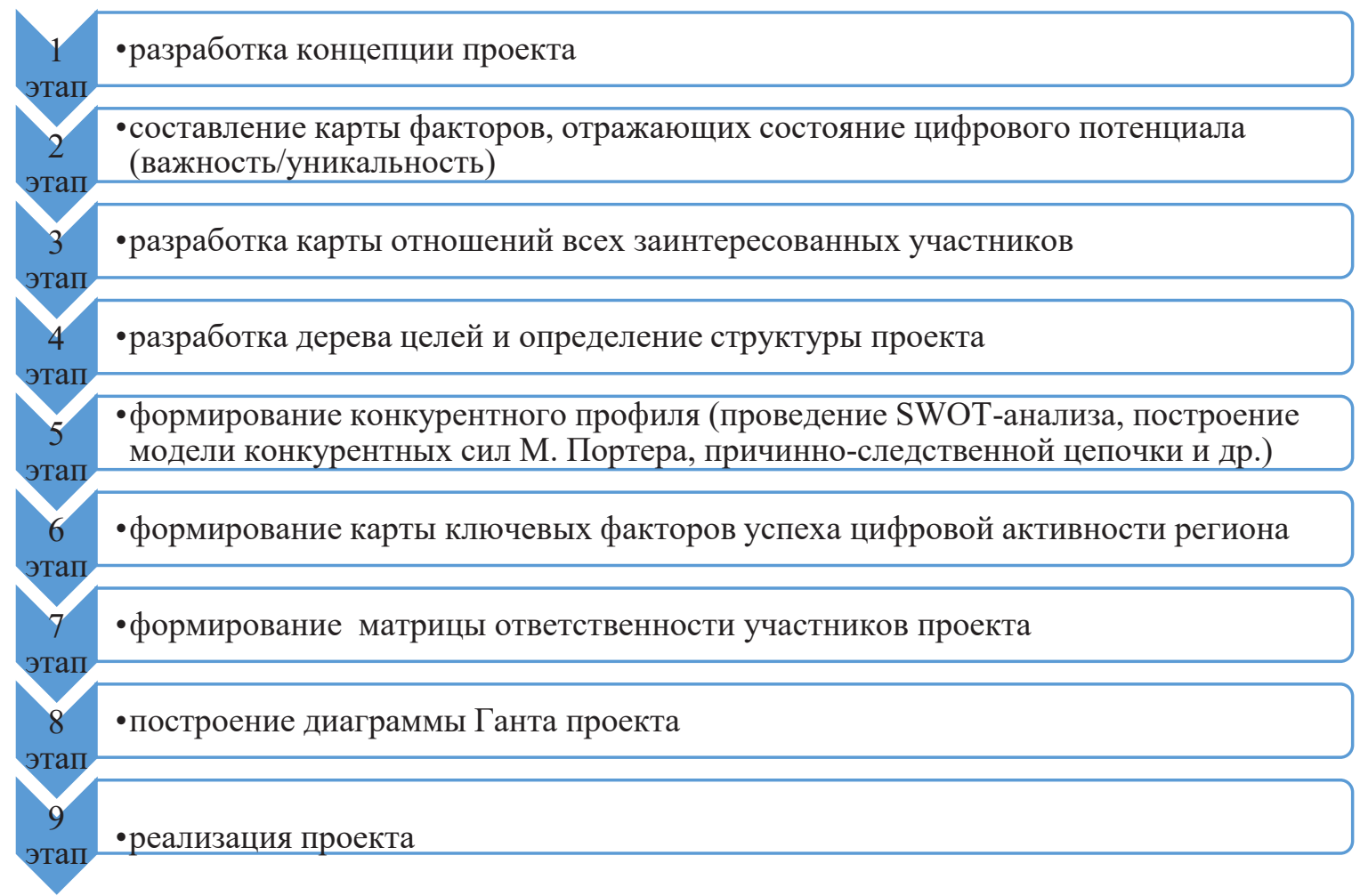

Рисунок 3. Предлагаемые этапы разработки Стратегии цифровизации региона с использованием проектного подхода 


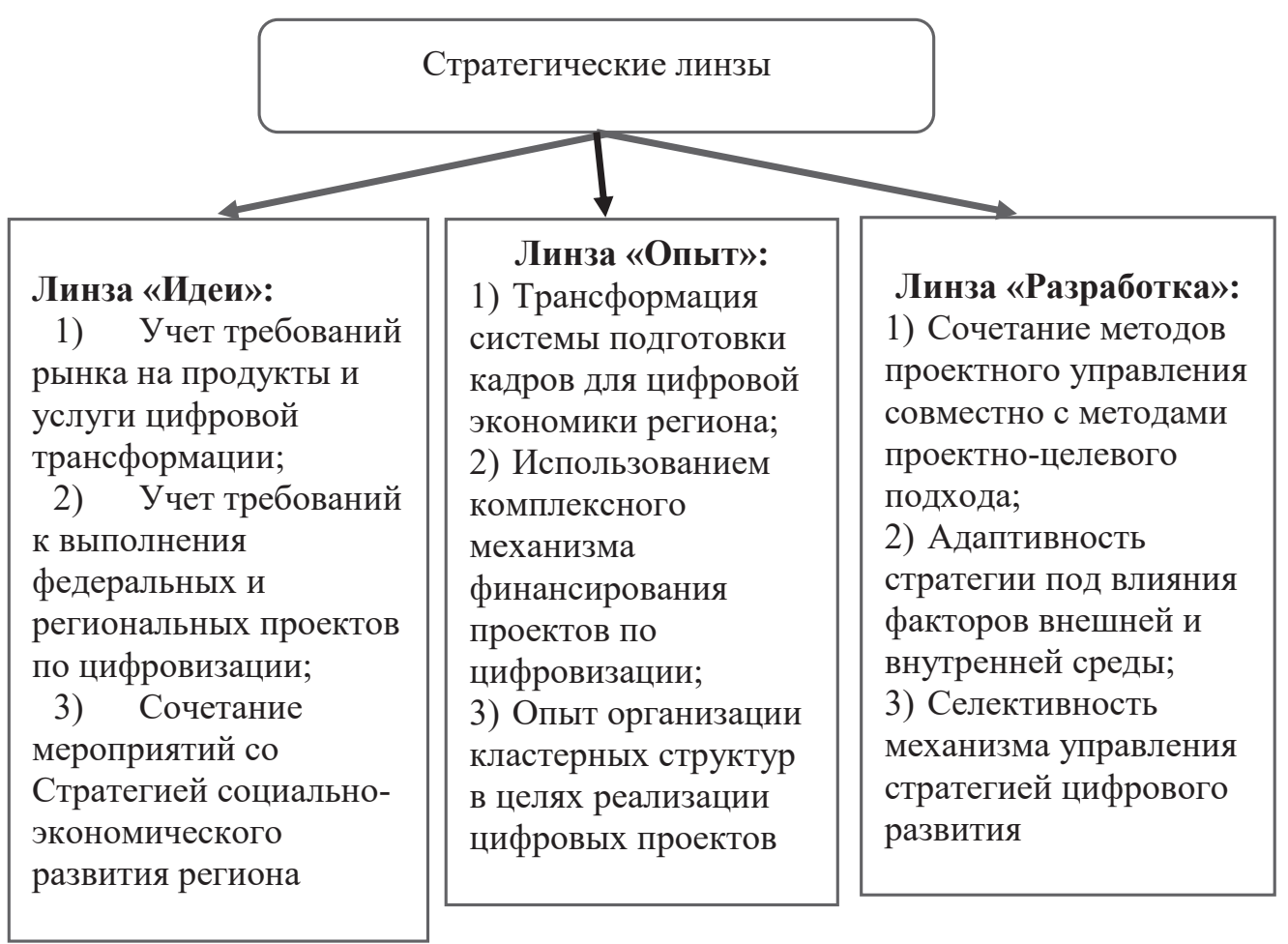

Рисунок 4. Авторский подход к разработке Стратегии цифрового развития региона на основе метода «Стратегических линз»

стратегического развития отраслей и владения методикой применения;

2) комплексное воздействие на цифровой сектор экономики региона, так как позволяет учитывать различные факторы экономического, социального, производственного и прочего характера;

3) сочетание мероприятий, указанных в программах развития, друг с другом;

4) прозрачность используемой информации и ее унифицированность для принятия соответствующих управленческих решений;

5) идеально применим для решения крупномасштабных проектов цифровой трансформации отдельных отраслей и секторов экономики;

6) способствует комплексному развитию региональной экономики в контексте с развитием экономик муниципалитетов, так как определяют единую траекторию цифрового развития;

7) является эффективным инструментом долгосрочного и среднесрочного планирования на основе определения приоритетов развития и средств их достижения.

Предлагаемый макет стратегической карты, определяющей уровень цифрового развития региона, представлен в таблице 2.

Контроль за своевременным заполнением исходной статистической информации и полу- ченными расчетными значениями должен быть возложен на руководителя структурного подразделения в составе Правительства региона, отвечающего за реализацию функций по координации процесса цифровой трансформации.

Мониторинг уровня цифрового развития региона должен осуществляться совместно с региональными проектными управлениями (офисами), так как данная структура наделена полномочиями по разработке и реализации региональных проектов, поэтому полученные данные должны быть доступны региональному проектному офису автоматически для оценки достижения целевых показателей региональных проектов по цифровой экономике, а также для синхронизации данных с другими взаимосвязанными региональными проектами.

Таким образом, использованием в практической деятельности регионов России предлагаемых инструментов организации системы мониторинга уровня цифрового развития региональных хозяйственных систем и элементов Стратегии цифровой трансформации позволит оперативно выявлять внутренние резервы снижения цифровой дифференциации и определять перспективные направления использования сквозных цифровых технологий в контексте обеспечения их устойчивого развития. 
Таблица 2. Предлагаемая стратегическая карта цифрового развития для оценки эффективности мероприятий по цифровой трансформации отдельных муниципалитетов (макет разработан авторами)

\begin{tabular}{|c|c|c|c|c|}
\hline Наименование муниципалитета: & $\begin{array}{l}\text { Фактическое } \\
\text { значение }\end{array}$ & $\begin{array}{c}\text { Прогнозные } \\
\text { значение }\end{array}$ & $\begin{array}{l}\text { Требуемый } \\
\text { объем финан- } \\
\text { сирования } \\
\text { мероприятий }\end{array}$ & $\begin{array}{c}\text { Соответствие } \\
\text { показателя } \\
\text { цели реги- } \\
\text { онального } \\
\text { проекта по } \\
\text { цифровизации }\end{array}$ \\
\hline \multicolumn{5}{|c|}{ Показатели, характеризующие цифровой потенциал } \\
\hline \multicolumn{5}{|l|}{$\begin{array}{l}\text { Удельный вес домашних хозяйств, имею- } \\
\text { щих широкополосный доступ к интернету, } \\
\text { в общем числе домашних хозяйств, \% }\end{array}$} \\
\hline \multicolumn{5}{|l|}{$\begin{array}{l}\text { Удельный вес продукции цифрового на- } \\
\text { значения в ВРП, \% }\end{array}$} \\
\hline \multicolumn{5}{|l|}{$\ldots$} \\
\hline \multicolumn{5}{|l|}{$\ldots$} \\
\hline \multicolumn{5}{|c|}{ Показатели, определяющие цифровую активность: } \\
\hline \multicolumn{5}{|l|}{$\begin{array}{l}\text { Удельный вес закупаемого (арендуемо- } \\
\text { го) отечественного ПО от общего объема } \\
\text { закупок продукции ИКТ назначения, \% }\end{array}$} \\
\hline \multicolumn{5}{|l|}{$\begin{array}{l}\text { Удельный вес организаций, использовав- } \\
\text { ших специальные программные средства } \\
\text { для научных исследований, \% }\end{array}$} \\
\hline \multicolumn{5}{|l|}{$\ldots$} \\
\hline$\ldots$ & & & & \\
\hline
\end{tabular}

\section{Библиографический список}

1. Бабкин А.В. Формирование цифровой экономики в России: сущность, особенности, техническая нормализация, проблемы развития / А.В.Бабкин, Д.Д.Буркальцева, Д.Г.Костень, Ю.Н. Воробьев // Научнотехнические ведомости Санкт-Петербургского государственного политехнического университета. Экономические науки. - 2017. - № 3.- С. 9-25.

2. Родионов Д.Г., Мугутдинов Р.М., Конников Е.А. Автоматизированный алгоритм системного анализа конкурентоспособности цифрового предприятия в рамках информационной среды // Экономические науки. 2021. № 200. С. 98-108.

3. Родионов Д.Г., Конников Е. А., Сергеев Д. А. Исследование механизмов взаимодействия субъектов цифровых экономических систем// Экономические науки. 2020. № 191. С. 25-31.

4. Родионов Д.Г., Конников Е.А., Алферьев Д.А. Информационный капитал предприятия как целевой показатель развития в рамках цифровых экономических систем // Экономические науки. 2020. № 190. С. $131-137$.

5. Постановления Правительства РФ от 31.10.2018 N 1288 (ред. от 24.06.2021) «Об организации проектной деятельности в Правительстве Российской Федерации» (вместе с «Положением об организации проектной деятельности в Правительстве Российской Федерации»)//http://www.consultant.ru/document/cons_doc_ LAW_310151/7d621220c2a686df7b51ded0e31e345ff3d4ad6a/

6. Харламов А.В., Харламова Т. Л. Трансформация российской хозяйственной системы: теоретические и практические аспекты// Известия Юго-Западного государственного университета. Серия: Экономика. Социология. Менеджмент. 2019. Т. 9. № 4 (33). С. 8-16.

7. Kharlamov A.V., Kharlamova T.L. Sustainable development of the Russian economy in the context of global instability. В сборнике: Proceedings of the 33rd International Business Information Management Association Conference, IBIMA 2019: Education Excellence and Innovation Management through Vision 2020. 33, Education Excellence and Innovation Management through Vision 2020. 2019. C. 822-830. 